\title{
Design, Tests and Repair Procedures for the Electrical Insulation of the Superconducting W7-X Magnets
}

\author{
Konrad Riße, Th. Rummel, G. Ehrke and M. Köppen
}

\begin{abstract}
The Wendelstein 7-X (W7-X) stellarator fusion experiment is presently under construction at the Max-PlanckInstitut für Plasmaphysik in Greifswald Germany. The W7-X machine has a superconducting magnet system with 50 nonplanar and 20 planar coils grouped in five equal modules. The operation of the $\mathrm{W} 7-\mathrm{X}$ machine requires a reliable insulation system of the superconducting magnets. Starting in the design phase the components have to consider the insulation system, weak points of the insulation must be identified and countermeasures must be taken, e.g. for the crossings of conductors inside the windings, the shape of handmade insulated areas and the quench detection cable design. The manufacturing has to be based on qualified procedures and materials, e.g. the vacuum pressure impregnation of the glass epoxy insulation as well as the hand-made glass epoxy wrappings must be thoroughly qualified and tested during the whole manufacturing process. A set of accompanying tests, especially high voltage tests, during the manufacturing and assembly process helps to assure the quality of the insulation.
\end{abstract}

Index Terms- Superconducting Magnets, Stellarator, Insulation, Insulation Testing

\section{INTRODUCTION}

$\mathrm{T}$ HE W7-X machine has a superconducting magnet system with 50 non-planar and 20 planar coils grouped in five equal magnet modules. All magnets are manufactured and the cryogenic acceptance tests at CEA in France were finished by the end of August 2009 [3,7,8]. The coil assembly is well in progress, $80 \%$ of the coils were already assembled. The first two magnet modules are nearly completely equipped with the support ring structure, different support elements between the coils, the superconducting bus system, cryogenic piping and instrumentation. The assembly of the outer cryostat wall will start at the end of 2009 [1,2].

During the operation of the W7-X machine high voltages will appear when the coil current has to be ramped down fast, thus a reliable electrical insulation is essential for the operation of the W7-X machine to insulate the high voltage components from earth potential. Defective insulation areas could lead to an arcing with a heavy damage of the insulation and surrounding components of the machine. Due to the limited

Manuscript received October 13, 2009.

Konrad Riße, Thomas Rummel, Gunnar Ehrke, Mathias Köppen are with the Max-Planck-Institut für Plasmaphysik, Euratom Association, Wendelsteinstraße 1, Germany 17489 Greifswald (phone: +49 3834 88-2720 fax: +49 3834 882709; e-mail: konrad.risse@ipp.mpg.de). accessibility the capabilities to detect a defect or to repair a defect are very restricted. This paper will describe the insulation system, the applied and proposed test procedures and necessary repair actions taking for example the non-planar coil magnets.

\section{NON-PLANAR COIL INSULATION SYSTEM}

\section{A. Requirements and Boundary Conditions}

The non-planar coils are specified for the following life cycle: 15 years life span, 50 cool downs to 4K, 5,000 full load cycles and 50 quenches. The insulation is specified to be composed of glass fiber reinforced epoxy materials and polyimide materials suitable for cryogenic conditions with a glass content $>60 \%$. The shear fracture strength must be $>55 \mathrm{MPa}$ at $4 \mathrm{~K}$ (40MPa at room temperature) and after 5,000 full load cycles $>30 \mathrm{MPa}$ at $4 \mathrm{~K}$.

The 10 coils of the same coil type are connected electrically in series to the power supply and the safety system equipped with the discharge resistors. During fast discharge of the magnet system the self induction of the coil circuit will cause a voltage. Without considering the mutual induction of the coil casings, the maximum resulting voltage over the magnets is calculated to be $\mathrm{U}_{\mathrm{FD}}=3.9 \mathrm{kV}$. The voltage over the single coil terminals amounts to $390 \mathrm{~V}[4,6]$. Due to the symmetric middle grounding of a coil group, the largest voltage against ground on the single coil is 0.5 times $\mathrm{U}_{\mathrm{FD}}$, which means $1.95 \mathrm{kV}$ under the condition that no undesired ground connection exists. In case of such an undesired ground connection by a faulty coil insulation the voltage can raise up to $\mathrm{U}_{\mathrm{FD}}$. The current is limited by the grounding resistors. To avoid disruptive discharges under partial vacuum conditions the insulation has to be gas tight.

\section{B. Design of the Insulation}

The winding pack of the non-planar coils has 108 turns of the especially developed W7-X Cable in Conduit Conductor (CICC) with a square cross section. The CICC is wrapped with $0.6 \mathrm{~mm}$ thick half overlapped glass tapes. Between the layers $0.4 \mathrm{~mm}$ thick glass mats were placed and between the double layers $0.8 \mathrm{~mm}$ thick glass mats were placed to form the inter turn insulation (see Fig.1).

The conductor ends of the double layers are routed in the connection area to the electrical joints and the coil terminals. The conductor in the connection area is insulated with $0.6 \mathrm{~mm}$ glass tapes, the empty space is filled with adapted G10 plates and glass rovings and the ground insulation of $5 \mathrm{~mm}$ is the 
same as on the whole winding. While inside the winding pack between the neighboring layers the voltage during fast discharge is lower than $33 \mathrm{~V}$, the voltage between the conductors in the connection area could raise up to $390 \mathrm{~V}$.

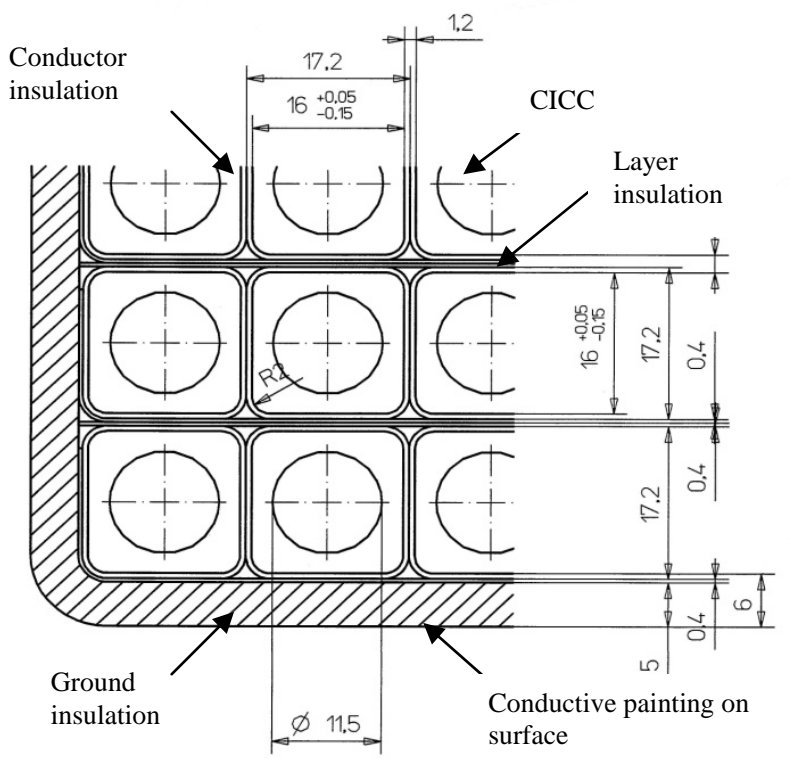

Fig. 1. Schematic view of a winding pack cross section with insulation details (coil casing not shown).

The whole winding pack with the exception of the electrical joints is Vacuum Pressure Impregnated (VPI) with epoxy resin. The border for this VPI is shown in Fig.2 (non-planar coils type 1 and 5 are slightly different). Above this VPI border the electrical joints and the coil terminals are insulated by handmade wet glass epoxy insulation. Due to the complicated design in this area it is important to pay attention on the design guidelines for a good high voltage insulation e.g. avoidance of sharp corners or hidden areas, smooth surfaces and geometries to suit the insulation manufacturing.

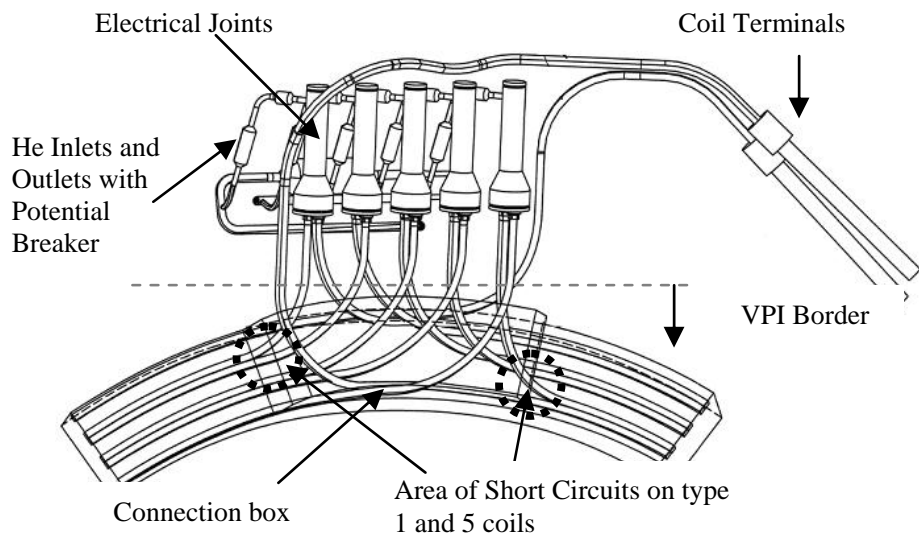

Fig. 2. Schematic view of non planar coil connection area (only winding pack shown without coil casing). VPI - vacuum pressure impregnation.

Quench Detection (QD) wires are connected to the electrical joints. The wires are collected in cables inside the connection area and exit the winding pack on top of the connection area at 3 points. Especially developed QD connectors connect the wires with the external shielded QD cable. A new QD cable was developed. It consists of 6 pairwise twisted Kapton insulated wires; each wire having its own screen. The cable is mechanically stabilized by an outer screen. The electrical joints connect the single double layers electrically and serve as He Inlet or Outlet. The potential separators assembled on the joints separate the grounded $\mathrm{He}$ supply pipes from the coil potential. Conductive paint is varnished on the outer surface of the winding pack ground insulation and connected to the ground potential of the coil casing. The conductive paint creates definite potential planes between the high voltage components and the ground potential.

\section{Test Program acc. to the original Coil Specification}

The technical coil specification requires final high voltage tests with full voltage during the work acceptance test while later tests have to be performed with gradually reduced test voltages; see Table I.

TABLE I

SPECIFIED HIGH VOLTAGE TESTS WITH GRADUALLY REDUCED VOLTAGE

\begin{tabular}{|c|c|c|c|}
\hline $\begin{array}{l}\text { Insulation } \\
\text { system }\end{array}$ & $\begin{array}{l}\text { Test } \\
\text { voltage }\end{array}$ & Duration & Condition \\
\hline \multirow[t]{3}{*}{$\begin{array}{l}\text { Ground } \\
\text { Insulation }\end{array}$} & DC $13 \mathrm{kV}$ & $1 \mathrm{~min}$ & $\begin{array}{l}\text { work acceptance test before } \\
\text { delivery; in air and at room } \\
\text { temperature (RT) }\end{array}$ \\
\hline & DC $10.4 \mathrm{kV}$ & $1 \mathrm{~min}$ & $\begin{array}{l}\text { during acceptance test at } \\
\text { cryogenic vacuum (4K) }\end{array}$ \\
\hline & DC $9.1 \mathrm{kV}$ & $1 \mathrm{~min}$ & repetition tests \\
\hline \multirow{4}{*}{$\begin{array}{l}\text { Inter Turn } \\
\text { Insulation }\end{array}$} & $\begin{array}{l}\text { AC } 2 \mathrm{kV} \\
2000 \mathrm{~Hz}\end{array}$ & $3 \mathrm{~s}$ & \multirow{4}{*}{$\begin{array}{l}\text { work acceptance test before } \\
\text { delivery in air at RT } \\
\text { during acceptance test at } \\
\text { cryogenic vacuum (4K) } \\
\text { repetition tests }\end{array}$} \\
\hline & AC $\quad 1,6 \mathrm{kV}$ & $3 \mathrm{~s}$ & \\
\hline & $2000 \mathrm{~Hz}$ & & \\
\hline & $\begin{array}{l}\mathrm{AC} 1,4 \mathrm{kV} \\
2000 \mathrm{~Hz}\end{array}$ & $3 s$ & \\
\hline
\end{tabular}

\section{Optimized Insulation Test PROGRAM}

Despite the electrical tests performed over the whole production period of the winding packs and the coil assembly process several heavy insulation defects were detected in advanced production steps. Such defects were mainly defective areas in the handmade insulation of the connection area with low glass content or air inclusions, winding short circuits and in addition to that the type 1 and 5 windings did not have a homogenous construction of the insulating filling material in the connection box. Based on the collected experiences several additional tests were implemented during manufacturing. A guideline for inspections and electrical tests regarding the high voltage insulation is proposed in the following chapter.

\section{A. Qualification Process for the Insulation}

The main properties of the insulation system were tested during the cold tests of the produced mock-up coil, the so called Demo coil. For this reason no contractual electrical qualification tests were required. The winding pack manufacturer qualified the mechanical quality of the inter turn insulation with a special shear strength test. Used materials and manufacturing methods i.e. the process for the conductor sandblasting, the primer application, the glass tape, the type of 
epoxy resin, the VPI procedure and the hardening process were qualified.

The main lessons learned are: To avoid individual defects on the insulation it is recommended to perform a comprehensive qualification of the working procedures. Special attention has to be paid to the handmade insulation: the glass tape wrappings must be fully penetrated with epoxy, tight wrappings and a strong pressing, e.g. by thermal shrinking tapes, helps to achieve the required glass content. Only specially trained and skilled workers guarantee the quality level; randomly taken samples should be regularly investigated to guarantee the insulation quality.

TABLE II

TESTS DURING THE WINDING PACK MANUFACTURING

\begin{tabular}{|c|c|c|}
\hline Production step & Tests & Comments \\
\hline \multirow{3}{*}{$\begin{array}{l}\text { Dry winding pack } \\
\text { (before VPI) }\end{array}$} & $\begin{array}{l}\text { Resistance } \\
\text { measurements }\end{array}$ & $\begin{array}{l}\text { Against ground and between } \\
\text { double layers, Test of QD wires. }\end{array}$ \\
\hline & AC voltage & $\begin{array}{l}\text { Application of voltage using the } \\
\text { transformer principle and pulse } \\
\text { discharge tests. }\end{array}$ \\
\hline & $\begin{array}{l}\text { Visual } \\
\text { inspection }\end{array}$ & $\begin{array}{l}\text { Cleanliness in workshop, check } \\
\text { of homogeneous glass wrappings, } \\
\text { clamping forces and QD wires } \\
\text { integrity. }\end{array}$ \\
\hline $\begin{array}{l}\text { Impregnation } \\
\text { process }\end{array}$ & $\begin{array}{l}\text { Recording of } \\
\text { process data }\end{array}$ & $\begin{array}{l}\text { Vacuum; pressure; temperature } \\
\text { vs. time; resistance measurement } \\
\text { of resin during curing. }\end{array}$ \\
\hline \multirow{4}{*}{$\begin{array}{l}\text { Impregnated } \\
\text { winding pack }\end{array}$} & $\begin{array}{l}\text { Visual } \\
\text { inspection }\end{array}$ & $\begin{array}{l}\text { Defects on the outer side are } \\
\text { visible like overpressed areas, } \\
\text { bubbles or non filled areas. }\end{array}$ \\
\hline & $\begin{array}{l}\text { Mechanical } \\
\text { tests }\end{array}$ & $\begin{array}{l}\text { Shear test on samples, e.g. } 9 \\
\text { conductor bundle tests. }\end{array}$ \\
\hline & $\begin{array}{l}\text { AC and DC } \\
\text { high voltage } \\
\text { tests }\end{array}$ & $\begin{array}{l}\text { Check of ground insulation or } \\
\text { inter turn insulation integrity with } \\
\text { full test voltage. To generate a } \\
\text { safety margin into the } \\
\text { manufacturing process the test } \\
\text { voltage should be e.g. } 30 \% \text { higher } \\
\text { than required and decrease over } \\
\text { the manufacturing period. }\end{array}$ \\
\hline & \multicolumn{2}{|c|}{$\begin{array}{l}\text { Measurement of impedance spectrum. } \\
\text { Measurement of insulation thickness by eddy current } \\
\text { testing. } \\
\text { Repetition of electrical tests; see chapter dry winding } \\
\text { pack, the impregnated winding pack could be loaded } \\
\text { with full test voltage. }\end{array}$} \\
\hline \multirow{4}{*}{$\begin{array}{l}\text { Winding pack } \\
\text { with completed } \\
\text { insulation }\end{array}$} & \multicolumn{2}{|c|}{$\begin{array}{l}\text { Repetition of electrical tests see chapter before. New } \\
\text { high voltage components were added e.g. QD wires. }\end{array}$} \\
\hline & $\begin{array}{l}\text { Visual } \\
\text { inspection }\end{array}$ & Inspection of added insulation. \\
\hline & $\begin{array}{l}\text { DC high } \\
\text { voltage test } \\
\text { under partial } \\
\text { vacuum } \\
\text { conditions } \\
\end{array}$ & $\begin{array}{l}\text { Sensible test of ground insulation } \\
\text { integrity with full test voltage. }\end{array}$ \\
\hline & $\begin{array}{l}\text { Test of QD wire } \\
\text { integrity }\end{array}$ & $\begin{array}{l}\text { The wires can be loaded with a } \\
\text { continuous DC current for } 1 \mathrm{~min} \text {, } \\
\text { check of contacts to the coil. }\end{array}$ \\
\hline
\end{tabular}

\section{B. Tests during the Winding Pack Production}

During the winding pack manufacture the insulation quality must be assured and checked by a set of various test procedures. It is proposed to implement a safety margin into the manufacturing process by an increased test voltage, e.g. $+30 \%$, which will be reduced gradually during the manufacturing steps until the final acceptance test in the workshop.

On the "dry" winding pack, which means before the VPI, the following main tests were performed: (1) measurement of the insulation resistance between the double layers with $500 \mathrm{~V}$ and the acceptance criteria $>0.5 \mathrm{Mohm}$; (2) pulse discharge tests on each double layer with $500 \mathrm{~V}$ peak voltage and evaluation of the resulting dumping curve. Further tests are proposed in Table II. The test results need to be documented and it is advised that the customer witness the tests. During the impregnation cycle the process data need to be controlled, recorded and evaluated.

The impregnated winding pack was loaded with the full test voltages of $13 \mathrm{kV}$ DC to check the ground insulation. The acceptance criteria for the leakage current was $<13 \mu \mathrm{A}$ corresponding to $1 \mathrm{GOhm}$ insulation resistance during the plateau phase of $1 \mathrm{~min}$. It is recommended to define these values in the technical specification. The pulse discharge tests were performed with $4 \mathrm{kV}_{\mathrm{pp}}$. At this manufacturing stage the $4 \mathrm{kV}_{\mathrm{pp}}$ voltage should also be applied using the transformer principle and the pulse discharge test as cross check. Measurements of the ohmic resistance of the windings, tests of the QD wire integrity and measurements at medium frequency should be performed in addition.
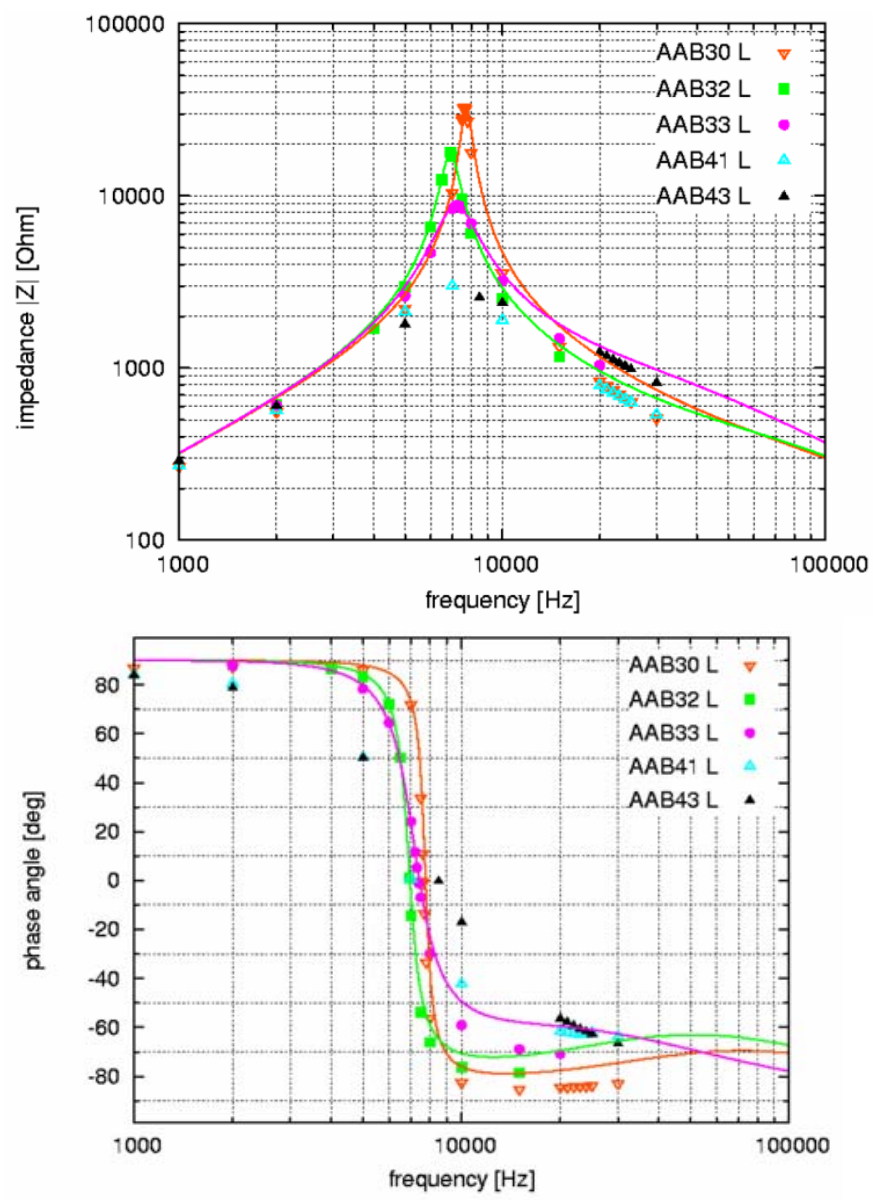

Fig. 3. Impedance and phase angle data measured from different winding packs with conductive painting combined with results from fitting the model network by the different parameters. All spectra can be fitted well except for coils AAB41 and AAB43, these data are under evaluation. 
The winding pack impedance was measured at a low frequency spectrum together with the phase angle (see Fig.3). Short circuits will be detected by a change in the resonance frequency; the impedance value is lower and the phase angle curve shape will change [5].

After the completion of the insulation a high voltage test under partial vacuum conditions (Paschen conditions) at room temperature is proposed as the most sensitive test of the ground insulation. The coil needs to be installed in a vacuum chamber, all high voltage components inside the vessel must be gas tight insulated, the conductor must be connected with the plus pole of the test voltage and the vessel needs to be connected with the minus pole. To detect defective areas a camera system inside the vessel has to record visible discharges. The computer controlled high voltage test system should perform the test automatically. It has to record the main data like: voltage, pressure, leakage current and camera pictures which will be the basis for the test report.

\section{Tests during the Coil Assembly}

During a final assembly step the coils were assembled into the stainless steel casings. The cooling system was installed onto the coil casings and the coils were equipped with sensors. The final work acceptance tests were performed before delivery. The ground insulation test at $13 \mathrm{kV}$ and the high voltage test under partial vacuum conditions were repeated. Due to the mutual inductance of the coil casing a special test device for the AC test of the inter turn insulation was developed by the Spitzenberger \& Spies company in Germany. An adapted capacitor battery works in resonance with the coil while the system is charged by a signal generator combined with an amplifier via a transformer up to $2 \mathrm{kV}$ at $2 \mathrm{kHz}$ for $3 \mathrm{~s}$.

The inductance and the frequency spectrum tests can be repeated, but the sensitivity to detect short circuits is reduced by the mutual inductance of the coil casings.

\section{REPAIR ACTIONS ON THE COIL INSULATION}

Repair actions on the inter turn insulation became necessary after the detection of short circuits on four winding packs of the type 1 and 5 (see Fig.2). In addition the connection box contained holes, gaps and resin rich areas. It was found that this area was not correctly filled with glass material, the pressing forces were too uneven and the impregnation process was not suitable for the connection box. These impregnation defects were detected lately during coil assembly by the high voltage test under partial vacuum conditions.

To repair the short circuits it was necessary to dig out the filling material in the connection box partially, to remove the short circuits and to reconstruct the connection box again. This reconstruction was done by adding individually shaped G10 pieces which were glued by a special resin. For this purpose the resin LY1025 with the hardener HY 219 and the accelerator DY 219 with a weight ratio 100:50:3 were qualified as glue. A short beam shear test was carried out to qualify the bonding between this glue to the winding pack with a resulting shear strength of $56 \mathrm{MPa}$ at RT. This resin system charged with translucent fused quartz powder
(Quarzgutmehl) was qualified for the purpose to fill the remaining holes. The surface of the holes was treated with pure resin for $1 \mathrm{~h}$ before the filling of the holes started. This procedure improves the surface contact between the hole surface and the charged resin. The coil temperature was held between $20-30^{\circ} \mathrm{C}$. For qualification purpose special samples were manufactured and thermally cycled to $77 \mathrm{~K}$ temperature for testing the shear strength, the high voltage behaviour and the leak tightness.

\section{CONCLUSIONS}

The design of the high voltage components has to consider the insulation which will be added during the manufacturing process. A rounded outer shape and a good accessibility without hidden areas help to manufacture the insulation and increase the quality. The efforts to create a reliable handmade insulation are often underestimated. The insulation manufacturing process must be thoroughly qualified and the workers must be very well skilled in this working field. The workshop for the winding and insulation work must be very clean to avoid any damage to the insulation system. A guideline of electrical tests has to be implemented to accompany the manufacturing process from the beginning on. It is recommended to implement a safety margin into the manufacturing process by an increased test voltage which will be gradually reduced during the manufacturing until the final acceptance test in the workshop. The customer should witness these tests. The test equipment for all electrical tests should be the latest state of the art, qualified for this purpose and should be identical in different workshops.

\section{ACKNOWLEDGMENT}

The work of H. Ehmler, J. Baldzuhn and M. Köppen regarding the impedance and phase angle measurements is gratefully acknowledged. Sincere thanks to R. Maix and H. Fillunger from Atominstitut Wien Austria, to all my colleagues from the W7-X team, to Mr. Wittenzellner from Spitzenberger\&Spies Company and to the manufacturers teams for their support and contributions to this paper.

\section{REFERENCES}

[1] L. Wegener, "Status of Wendelstein 7-X Construction," Fusion Engineering and Design, 84 (2009), pp. 106-112.

[2] H.-S. Bosch, "Wendelstein 7-X a technology step toward Demo," to be published in Plasma and Fusion Research 2009.

[3] K. Hertel, "Test of Superconducting Coils for the Wendelstein 7-X Stellarator Experiment,“ to be published in IEEE Transactions on Applied Superconductivity.

[4] M.Köppen, "Simulation of voltage and current development in the Wendelstein 7-X coil system taking into account fault conditions," Fusion Engineering and Design, 82 (2007), pp. 1549-1554.

[5] H. Ehmler, "AC modelling and impedance spectrum tests of the superconducting magnetic field coils for the Wendelstein 7-X fusion experiment," Review of Scientific Instruments, 78, 104705 (2007).

[6] M. Köppen, "Simulations of W7-X magnet system fault scenarios involving short circuits," Fusion Engineering and Design, 84 (2009), pp. 1104-1107.

[7] H. Viebke, “Acceptance tests of W7-X coils," Fusion Engineering and Design, 84 (2009), pp. 1925-1927.

[8] G. Croari, "DC insulation tests of W7-X coils at CEA, Saclay," Fusion Engineering and Design, 84 (2009), pp. 632-635. 